\title{
DE VEETEELT IN SURINAME
}

DOOR

\section{J. J. LEYS}

Zooals bekend is, heeft Gouverneur Baron van Heemstra bij zijn optreden als Gouverneur van Suriname beloofd, plannen uit te werken, waardoor de economische opbouw van de kolonie voor lange jaren zou verzekerd zijn. Natuurlijk vestigde hij al dadelijk zijn aandacht op kolonisatie, op uitbreiding en verbetering van den landbouw en op de bevordering van de veeteelt. Vandaar dat hij in 't begin van 1922 twee commissies in 't leven riep: een, die het vraagstuk der kolonisatie van Suriname onder de oogen moest zien, en een andere, die onderzoeken moest in welke richting, de Surinaamsche veeteelt zich diende te ontwikkelen, niet alleen om een bron van bestaan te vormen voor den tegenwoordigen veeteeler, maar ook voor die toekomstige kolonisten, die zich meer aangetrokken zouden gevoelen tot het uitoefenen van de veeteelt, dan van den landbouw.

De commissie, ingesteld op 22 Februari 1922 bestond uit acht leden. Voorzitter was de gouvernements-veearts. Met bekwamen spoed ging de commissie aan 't werk, vergaderde eens per maand en bracht binnen het jaar een uitvoerig verslag uit van haar werkzaamheden. Dit rapport zou in „West Indië” worden gepubliceerd.

\section{ALGEMEENE TOESTAND VAN DEN VEESTAPEL.}

De officieele opgaven van het aantal runderen, ezels, paarden en varkens zijn te vinden in de jaarverslagen van het Departement van den Landbouw. Om ons voorloopig alleen te bepalen tot den rundveestapel, blijkt daaruit, dat het aantal koeien sterk vooruit gegaan is na 1914. Dit 
is in hoofdzaak toe te schrijven aan het feit, dat de van contract vrijgekomen Britsch Indiërs zich meer op de rundveeteelt gingen toeleggen dan voor 1914. Het aantal kleine landbouwers werd voortdurend vergroot door vrijgekomen Britsch Indische arbeiders, die van hun recht op vrijen terugvoer naar hun land afzagen; daarvoor een premie van honderd gulden ontvingen en het recht om zich te vestigen op een stukje grond ter grootte van een tot twee H. A., om daarop landbouw en veeteelt uit te oefenen op een der Gouvernements vestigingsplaatsen.

$\mathrm{Na} 1914$ werd deterugkeer naar Britsch-Indiëvoor de immigranten trouwens zeer moeilijk bij gebrek aan scheepsgelegenheid. Opnieuw een contract sluiten voor vijf jaar doet een Britsch-Indiër hoogst zelden. Die dus in oorlogsjaren vrij kwam van contract en toch niet terug kon naar zijn vaderland, bleef in Suriname hangen en was meestal noodgedwongen verplicht, zich als kleine landbouwer te vestigen. Velen voeren daar wel bij. De hooge prijzen, die ze maakten voor de door hen verbouwde levensmiddelen, voor de melk en voor hun vee waren oorzaak, dat velen in goeden doen kwamen en er niet meer aan dachten terug te keeren naar Voor-Indië, te meer daar de berichten omtrent den toestand in VoorIndië alles behalve gunstig luidden. Met de toename van het aantal kleine BritschIndische landbouwers ging ook gepaard de toename van het aantal runderen. Iedere Britsch-Indiër streeft er naar om een of meer koeien op stal te hebben. Ik zou haast zeggen in huis te hebben. De uiterst primitieve woningen, beter gezegd, hutten dier Aziaten, zijn dikwijls zoo ingericht, dat de koeienstal een afdeeling is van 't woonhuis. In den vollen zin des woords is de koe voor den BritschIndiër een huisdier, voor den Hindoe is het zelfs een heilig dier en al is dit voor den Mahomedaan niet het geval, hij vereert toch zijn koe en verzorgt haar beter dan zijn eigen vrouw en kinderen.

Onder de van contract vrijgekomen Javanen, die zich als kleine landbouwers in de kolonie hebben gevestigd, zijn er maar enkele, die zich op de veeteelt toeleggen. Ze hebben daarbij meestal een andere bedoeling dan de 
Britsch-Indiërs. De laatsten leggen zich op de rundveeteelt toe om de melkopbrengst. De eersten kweeken een koe- of een stierkalf, dat ze voor vijftien à twintig gulden gekocht hebben, om het als volwassen koe of stier aan andere veeteelers of aan den slager te verkoopen. Ze hebben dan een sommetje geld bij elkaar om eens goed feest te vieren, om te verdobbelen, om een vrouw te koopen of sieraden voor de wederhelft aan te schaffen; soms ook om een grondje of een opstal te koopen. Vooralsnog zijn de Javanen in Suriname geen veeteelers.

Onder beide Aziatische volksstammen zou de veeteelt ongetwijfeld van grooter beteekenis zijn, als ze zich hier, evenals in hun vaderland, toelegden op de fokkerij van trekvee. Daar schijnt men echter in Suriname niet aan te willen. Men schijnt niet te willen gelooven aan de groote beteekenis van den os als trekdier. Doch hierover later.

In de periode van 1900-1914 ging de rundveestapel vooruit met 569 stuks, dat is dus gemiddeld 41 stuks per jaar. Dit is een toename, die van geen beteekenis is. $\mathrm{Na}$ 1914 wordt het beter. In de zevenjarige periode van 1914 -1921 vermeerderde het aantal runderen met 4748, dus gemiddeld met 678 stuks per jaar. Vooral in de jaren 1918 en 1919 was de toename buitengewoon sterk, ze bedroeg niet minder dan 2700 stuks in een jaar. $\mathrm{Nu}$ is er op deze cijfers wel iets aan te merken. Dit wordt ook erkend in het jaarverslag van het Landbouwdepartement over 1922. Daar wordt nl. gesproken over de groote moeilijkheid, die er in gelegen is om in Suriname betrouwbare gegevens te krijgen omtrent den veestapel. De enorme uitgestrektheid der kolonie, het afgelegene van sommige landbouwbedrijfjes, waarvan verscheidene, gedurende een groot deel van 't jaar niet te bereiken zijn, vanwege het water en de modder, zijn hiervan de oorzaken. De politie-agenten, die de gegevens moeten verzamelen zijn gewoonlijk niet zoodanig overtuigd van 't belang der zaak, dat zij persoonlijk een onderzoek instellen bij de meest afgelegen wonende landbouwers. Ze stellen zich vaak tevreden met mededeelingen van derden, die het ook niet zeker weten. Zoo komt het, dat de officieele opgaven in den regel veel te 
laag zijn. Daardoor is het te verklaren, dat, wanneer er eens een meer nauwkeurige veetelling wordt gehouden, het officieele cijfer voor dat jaar een reuzensprong maakt, naar boven, een sprong die niet te verklaren is door geboortetoename in den veestapel, noch door het zich vestigen van meerdere kleine veeteelers,

De opmerking in genoemd jaarverslag van het Landbouw-departement, als zouden de officieele cijfers, door het Landbouwdepartement zelf gepubliceerd, onbetrouwbaar zijn, omdat de opgave van het aantal stuks vee veel te hoog is, is dan ook volgens alle deskundigen geheel bezijden de waarheid. Men staat er over verbaasd, dat het Landbouwdepartement zijn eigen cijfers, die het sedert 16 jaren heeft gepubliceerd onbetrouwbaar durft noemen. Zoo iets zal zeker zelden voorkomen. Men zou zich kunnen voorstellen, dat het Departement door een nauwkeurig onderzoek tot het inzicht was gekomen, dat de tot hiertoe gevolgde methode van veetelling steeds te hooge uitkomsten leverde. In dat geval zou de Departement's chef zeggen: ,'t Spijt me zeer, dat we tot hiertoe onwillens te hooge opgaven hebben verstrekt, voortaan zullen de gepubliceerde getallen door een verbeterdewijzevan tellen, een getrouwer voorstelling geven van het aantal stuks vee.

Niets van dat alles.

Het Landbouwdepartement keurt zonder eenig nader onderzoek, met een onbegrijpelijke lichtvaardigheid zijn eigen cijfers af, voert geen nieuwe wijze van telling in, en publiceert in volgende verslagen de gegevens omtrent den veestapel, die op dezelfde wijze verkregen zijn als de vroegere, die zoogenaamd niet deugden. Dat onbegrijpelijke wordt begrijpelijk, alswe het jaarverslag vanden Landbouw over 1922 lezen in verband met het verhandelde in de vergadering der Koloniale Staten van 21 Sept. 1921, waarin behandeldwerdhet beruchteslachtverbod.Ookhieroverlater.

De Commissie, die in 1903 belast was met het zoeken naar middelen om den Surinaamschen rundveestapel te verbeteren, sprak als haar meening uit, dat de rundveestapel, die toen ongeveer 7000 stuks runderen telde, ontoereikend was om in de behoefte aan versch vleesch te 
voorzien. Om in dat vleeschtekort te voorzien, moesten er jaarlijks van 500 tot 1000 runderen uit Demerara en Venezuela worden aangevoerd. Dat waren dan meestal savanna-ossen, die in genoemde landen, op de uitgestrekte schrale savanna's zoo goed als in 't wild waren opgekweekt.

Over het algemeen eet de bevolking van Suriname het vleesch dezer dieren niet gaarne, het is in den regel taai. Veel beter vleesch leveren de Surinaamsche koeien en stieren, (ossen zijn er niet), omdat het malscher is. We noemen het Surinaamsche vee gewoonlijk Creoolvee. Bij gebrek aan Creool slachtvee moest men echter wel savanna slachtvee invoeren om aan de vraag naar versch vleesch te voldoen. Die vraag zou nog grooter zijn, als de bevolking meer versch vleesch at. Het goedkoopere Amerikaansche zoutvleesch, dat in enorme hoeveelheden ingevoerd wordt is ook een van de oorzaken, dat er niet zooveel runderen worden geslacht als er geslacht konden worden, de sterkte der bevolking in aanmerking genomen.

De oorlogsjaren hebben wonderen verricht ten opzichte van den Surinaamschen rundveestapel. Het aantal koebeesten is zoodanig uitgebreid, dat we ten opzichte van ons slachtvee onafhankelijk geworden zijn van 't buitenland. Wel voeren enkele handelaars zoo nu en dan een scheepslading savanna vee in, maar de geringe winsten, die ze soms maken, en de groote verliezen, die ze dikwijls lijden, zijn oorzaken, dat de invoer van slachtvee tegenwoordig weinig beteekent.

We zijn dus ten opzichte van onze versch-vleeschvoorziening niet meer afhankelijk van onze buren. Met kracht is daarnaar gestreefd sedert 1903. Na twintigjarige zorg besteed te hebben aan onzen rundveestapel, is dat doel bereikt. Allerlei factoren hebben medegewerkt om de zorgen van het Landbouwdepartement voor onzen veestapel met succes te bekroonen en al is de gunstige uitslag niet alleen een gevolg van de actie uitgaande van het Departement, maar in hoofdzaak van de toename der vrije bevolking, toch mag gezegd worden, dat er van Gouvernementswege heel wat gedaan is om den rundveestapel te verbeteren en 
uit te breiden; want het kwam niet alleen aan op vermeerdering van 't aantal runderen, maar ook op verbetering van 't gehalte der dieren.

Landbouw en veeteelt worden in de kolonie gedreven op zeer extensieve wijze, Van het fokken in de melkrichting of in de vleeschrichting, daarvan weet men niets af. Een veefokker heeft een troep koeien in een weide loopen, een stier loopt er tusschen. Het dekken geschiedt dus in 't wild. Of een koe drachtig is weet men pas als het uitwendig zichtbaar wordt. Wanneer zoo'n koe kalven moet is onbekend, er wordt maar gegist. Veelal gebeurt het, dat een kweeker op zijn weiland komt en daar een kalf vindt, dat den vorigen dag geboren is. Dat kalf blijft verder bij de moeder en zuigt zooveel melk als het op kan, de boer moet zich tevreden stellen, met wat er over schiet. Gevolg van een en ander is geweest, dat er van teeltkeus nooit sprake was. Wanneer de kalveren aangehouden werden, liepen ze als vaarzen ook in den troep mee en werden gedekt door den stier, die hun vader was. Familieteelt was bijnna regel.' De ḱoeièn en stièren waren dản ook over 't 'al-' gemeen ellendige beestjes. Ze waren het best te vergelijken met de Drentsche runderen, zooals men die in die provincie zag een veertig jaar geleden. Klein, mager, slecht bestand tegen ziekten, terwijl de melkproductie gering was. Van particuliere zijde werden weleens pogingen in 't werk gesteld, om behoorlijk vee te fokken, maar deze particuliere fokkerijen hebben er zeer weinig toe bijgedragen om den rundveestapel in de kolonie te verbeteren. 't Ging bij die particulieren ook meer om vleesch dan om melk. Bovendien zondigden die ondernemende particulieren heel dikwijls tegen de allereenvoudigste regels volgens welke de veeteelt beoefend moet worden. Hun verliezen waren dikwijls enorm en zoo hebben ze langzamerhand afgezien van de fokkerij om die over te laten aan de boeren en de Britsch-Indische kleine landbouwers, die toch altijd eenige meerdere zorg aan hun vee konden besteden.

Een groot ongerief en een struikelblok op den weg naar verbetering van den veestapel was het zuigen der kalveren. Geen enkele boer of kleine landbouwer kon eenigs- 
zins nauwkeurig opgeven hoeveel melk deze of die koe gaf. Vroeg men er naar, dan kreeg men ten antwoord: „Die geeft vier flesschen, die twee”; soms ook hoorde men wel eens van een koe, die zeven flesschen melk gaf. Die opgaven waren niet erg betrouwbaar, bovendien was dit de opbrengst van de koe, nadat het kalf eerst zijn buik had volgezogen. Gewoonlijk ging het zoo: Als een veehouder 's morgens zijn koe ging melken, dan werd eerst het kalf erbij gebracht. Dat zoog tot het zijn buik bijna vol had. Dan werd het van de moeder weggetrokken en zette de melker zich onder de koe om er nog uit te halen, wat er nog in zat. Die melk werd door een doek gegoten en in literflesschen gedaan. De gevulde literflesschen werden zonder stop er op in een bakje geplaatst of in een karretje gezet en naar de stad gebracht. Zoo komt het, dat men in Suriname de melkopbrengst der koeien uitdrukt, niet in Liters, maar in flesschen. In de tropen is het afleveren van melk in flesschen aan consumenten ook de meest geschikte manier, mits natuurlijk de flesschen goed schoon gehouden worden.

$\mathrm{Nu}$ is het gemakkelijk in te zien, dat er van een oordeelkundige fokkerij geen sprake kan zijn, als een boer niet weet hoeveel melk zijn koeien produceeren. Aan selecteeren, aan het uitzoeken van de beste melkgeefsters voor de fokkerij valt niet te denken, en dat moet toch, wil men de inkomsten van zijn rundveestal zoo hoog mogelijk opvoeren. Sprak men met de boeren en kleine landbouwers over het verkeerde van de gewoonte om de kalveren te laten zuigen, dan kreeg men steeds ten antwoord: ,,Als we de kalveren niet laten zuigen, dan laten de koeien hun melk niet schieten". Nu was daar wel iets van aan. Door het invoeren van Zebu stieren had men hier een kruisingsproduct gekregen, dat half en driekwart Zebu was. Van het Zebu rund is het bekend, dat het moeilijk gemolken kan worden, als het kalf de uier niet eerst aan den gang heeft gezet door te zuigen. Of dit met alle Zebu rassen het geval is, zou ik niet durven beweeren, maar voor het ras, dat in Suriname is ingevoerd, en dat jammer genoeg later bleek, juist het ras te zijn dat weinig melk gaf en in Indië hoofd- 
zakelijk als trekdier wordt gebruikt, schijnt het wel het geval te zijn. Hadden de veehouders in hun kudde een Zebu stier loopen dan was na verloop van eenige jaren de heele veestapel half en driekwart Zebu. In dat geval zal het melken zeker moeilijkheden opgeleverd hebben. Rekent men nu verder met de gemakzucht van sommige tropische landbouwers en veefokkers, dan is het te verklaren, dat ze de kalveren maar lieten zuigen. Het melken ging dan gemakkelijker en wat ook van beteekenis was, men had dan de kalveren niet afzonderlijk te voederen.

Tot 1916 vond men dezen toestand op alle boerderijen rondom Paramaribo. $\mathrm{Na}$ die jaren is er geleidelijk verandering in gekomen en zijn de veeteelers, waaronder de Hollandsche Boeren in de eerste plaats, begonnen met de kalveren direkt na de geboortevan de moeder af te nemen. Dit is een der weinige vruchten van het toen gegeven landbouwonderwijs.

Onder de pogingen door het Gouvernement aangewend, om den rundveestapel te verbeteren, behoort het invoeren van Zebu runderen, waarover we straks spraken. Dit rundveeras behoort thuis in VoorIndië. Onze BritschIndiërs kenden het dus, dat was al een groot voordeel. Het Zebu rund is een forsch, sterk gebouwd, groot beest, licht grijs van kleur met een vetbult op de schoft en een enorm kossem (huidplooi onder de keel). Zoo'n Zeburund maakt op ieder, die het ziet, den indruk van kracht. De zwakke uierontwikkeling wijst op een geringe melk productie. Daar zijn echter Zebu runderen, o. a. die welke behooren tot het Ongola ras, die ook goede melkgeefsters zijn. Waarom men die niet invoerde? In de eerste plaats, omdat de goede eigenschappen van dit ras in het begin dezer eeuw in Suriname nog niet bekend waren. In de tweede plaats, omdat we niet uit Britsch-Indië aanvoerden maar uit Trinidad. Daar kende men reeds lang de goede eigenschappen van het Zebu-rund als trekdier en als een dier, dat geschikt is om met het inlandsche ras te kruisen of dit laatste wat krachtiger te maken en meer bestand tegen allerlei ziekten, vooral tegen de gevaarlijke Texas-koorts. De kruisingsproducten voldeden tamelijk 
wel, omdat men weinig lette op de melkopbrengst. Zoo kwam het, dat het Surinaamsche gouvernement en enkele particulieren uit Trinidad, Zebu stieren lieten overkomen om met het Creoolvee in Suriname te kruisen. Die ingevoerde stieren hebben een gunstigen invloed uitgeoefend op den rundveestapel. De familieteelt werd er eenigszins door tegen gegaan: er kwam nu vreemd bloed in den veestapel. De kruisingsprodukten: koeien en stieren waren grooter en zwaarder dan de inheemsche dieren, ze waren minder onderhevig aan ziekten, maar de melkopbrengst per koe ging er niet op vooruit. De totale melkopbrengst steeg echter, omdat men meer koeien ging houden, en omdat men er minder verloor door ziekten.

Enkele particulieren voerden ter verhooging van de melkopbrengst Schorthorn- en Red Pol-stieren in, uit Demerara ; een enkele zelfs waagde het Hollandschestieren in te voeren; hier en daar zag men ook een Guernsey stier. Ongetwijfeld hebben die pogingen van 't gouvernement en van particulieren er veel toe bijgedragen om onzen rundveestapel voor algeheele degeneratie te bewaren. Toch heeft men er niet mee bereikt, wat men op Trinidad en Demerara heeft bereikt, omdat in Suriname de invoer van rasbeesten niet geschiedde volgens een weloverlegd plan, en men niet doelbewust streefde om een vast type rundvee voor Suriname te fokken. Men kan dit den particulieren veefokkers zeker niet als fout aanrekenen. Het gouvernement gaat in dezen niet geheel vrij uit. De zuinigheid heeft ook hier de wijsheid bedrogen, al was het alleen maar hierin, dat men niet getracht heeft een man als Van der Schroeff, gouvernements veearts, voor Suriname te behouden. Had hij hier eenige jaren langer mogen werken en had men hem de middelen verschaft om de maatregelen te nemen, die hij noodig oordeelde, Suriname zou op dit oogenblik zeker een betere rundveestapel hebben.

De Hollandsche Boeren, die zich een 80 jaar geleden in de kolonie gevestigd hebben, behooren tot de beste veeteelers. $\mathrm{Ze}$ hebben per hoofd de meeste koeien. Vooraanstaande veeteelers zijn ook de eigenaars der 
voormalige plantages „Beekhuizen” en "Zorg en Hoop”.

Daar het aantal vrijgekomen Britsch-Indische landbouwers in de laatste jaren sterk toegenomen is en iedere Britsch-Indiër, als hij er eenigszins de kans toe ziet, een of meer koeien houdt, overtreft tegenwoordig het aantal hunner koeien, dat der Hollandsche Boeren verre, De Hollandsche Boeren worden dan ook langzamerhand van de melkmarkt verdrongen door de Britsch-Indiërs, zooals deze hen vroeger reeds van de groentemarkt verdrongen. Was de melkprijs tot 1 Januari 1923 nog een kwartje per Literflesch, in de maand Juni van dat zelfde jaar, werd ze al aangeboden voor 15 cent per Liter in 't groot. De klanten betaalden toen 20 cent per Liter. Waar een Surinaamsche koe gemiddeld niet meer melk produceert dan $4 \mathrm{~L}$. per dag, is de opbrengst van een koe dus al heel gering. Wanneer die opbrengst door prijsdaling straks gehalveerd wordt, dan is het duidelijk, dat onze boeren een kwaden tijd tegemoet gaan.

\section{DE VOEDERING VAN HET VEE.}

Een der oorzaken van de geringe melkopbrengst moet gezocht worden in de onvoldoende voedering der koeien. De Hollandsche boeren hebben uitgestrekte weidegronden rondom hun woonhuizen. Men meene echter niet, dat zoo'n Surinaamsche wei er even mooi uitziet als een Hollandsche wei. Van malsche groene weiden is daar nooit sprake. 't Zijn groote grasvlakten, die gedeeltelijk begroeid zijn met harde grassoorten, die hier en daar meer lijken op bosch dan op wei, die tal van hoog opschietende onkruiden dragen, die 't weinige gras, dat er nog groeit verstikken en die voor een groot deel van 't jaar deels onder water staan, deels in modderpoelen veranderen. Een behoorlijke afvoer van de geweldige massa's regenwater is nergens te zien. De slooten, die het water moeten afvoeren zijn deels dicht gegroeid met onkruiden en kleine en groote boomstompen; het dwarsprofiel is veel te klein; sommige zijn niet meer dan kleine greppeltjes en wat de deur dicht doet, de meeste hebben geen of slechts een zeer 
onvoldoende afwatering. Onder die omstandigheden is het natuurlijk onmogelijk behoorlijke weiden met een overvloed van goede grassen aan te leggen. Het doet vreemd aan, om in de maanden Mei tot Augustus de koeien tot aan hun buik in het water te zien plassen om de toppen af te vreten van de grassen, die boven het water uitsteken. In den drogen tijd zien de weiden op de kleigronden er nog treuriger uit. De overal gebarsten grond is zoo hard als steen. Is eenmaal het gras afgevreten, dan komt er geen nieuw gras voor in de plaats vóór de regens invallen. Ongetwijfeld zou er al veel gewonnen zijn, als men een behoorlijk stelsel van afvoer-slooten groef. De weideoppervlakte zou er door vergroot worden, doordat een groot deel der zwampen droog liep, terwijl de kwaliteit der grassen verbeteren zou. Bovendien zou de zode in den regentijd minder stuk getrapt worden. Maar de boeren kennen nog niet de zegeningen van onderlinge samenwerking en daardoor blijft de toestand zooals ze is.

De Britsch-Indiërs houden er voor hun koeien geen weiland op na. Zehouden hun beesten voortdurend op stal en voeren ze daar met gras, dat door man, vrouw en kinderen gesneden wordt, overal waar ze 't vinden kunnen. Bij 't zoeken van veevoer ontzien ze zich niet, hier en daar ook eens wat gras weg te halen, dat aan anderen behoort.

Het kwantum voer, dat de koeien der Britsch-Indiers krijgen is grooter dan de hoeveelheid voer, dat de koeien der Boeren krijgen, daarom zien de stalbeesten der eersten er over 't algemeen beter uit, dan de weiderunderen der laatsten.

Het spreekt van zelf, dat waar de opbrengst der koeien zoo gering is, de boeren geen groote kosten kunnen besteden om hun weidegronden te verbeteren. Konden ze nu een behoorlijke hoeveelheid voer verbouwen, dan ware er op die wijze ongetwijfeld eenige verbetering aan te brengen, maar dat is ook haast niet te doen.

In de eerste plaats hebben de landbouwers en veeteelers in Suriname niet zoo'n verscheidenheid van gewassen, die als voedermiddelen geschikt zijn, als waarover deNederlandsche veeteelers beschikten. Hier is geen klaver of 
lucerne, geen spurrie of seradela geen stroo of hooi; hier zijn geen wortels of knollen of aardappels. Al dergelijke voedergewassen, die in Nederland zoo'n groote rol spelen, mist men in Suriname. Bovendien zijn er zoo goed als geen afvalproducten van fabrieken, geen veekoeken, geen meelsoorten, geen granen, boonen of erwten. We hebben niets anders dat wat gras, wat zemelen wat melasse, en wat zoete pataten.

Daarbij komt nog een ander bezwaar. Gesteld, we konden een drie of vier soorten voedergewaasen verbouwen, dan moest daarvoor een deel van 't bouwland afgezonderd worden. Daarop kon dan als hoofd- of als tweede gewas, veevoer worden verbouwd. $\mathrm{Nu}$ hebben de Boeren, die toch de grootste landbouwers zijn, heel weinig bouwland. De grootste Boeren niet meer dan vier à vijf $\mathrm{H}$. A. Hierop worden gewassen verbouwd voor de markt te Paramaribo en voor eigen gebruik: bananen, cassave, pataten, boontjes, meloenen, enz. Om dit bouwland te gebruiken voor den verbouw van veevoer, zou niet betalen, want het spitten en bemesten van den grond kost zooveel aan arbeidsloon, dat de opbrengst aan veevoer de onkosten van aanleg en onderhoud op geen stukken na dekken zou. Dit kan anders worden zoodra de Boeren met trekbeesten gaan werken en hun bouwland, in plaats van om te spitten, omploegen. Dan doet men in één dag het werk, waartoe men anders een week noodig heeft. Men moet er zich over verbazen, dat de Boeren dat nog niet al lang hebben ingezien. Dat ze niet al over lang gebroken hebben met die primitieve methode van grondbewerking en in plaats van den Surinaamschen houwer allang niet gebruik gemaakt hebben van ploeg, eg, cultivator, zeis en maaimachine. Ze hebben zich aangepast aan de werkwijzen en aan 't gebruik van werktuigen, die ze in Suriname vonden, in plaats van de werkmethoden toe te passen, die in beschaafde landen worden gevolgd. Gelukkig komt er te dien opzichte eenige verandering. Men ziet al een enkele ploeg met een span trekossen gebruiken, terwijl er in den, laatsten tijd heel wat zeisen in gebruik zijn genomen. Eerst wanneer er allerwegen gebruik gemaakt wordt van den 
ploeg, kan men veevoer verbouwen in voldoende hoeveelheid, voer, dat aan de eischen voldoet, van onderhoudsvoer en van krachtvoer, want aan dat laatste ontbreekt het ons geheel.

In de laatste jaren zijn er vanwege het Landbouwdepartement pogingen aangewend om den verbouw van veevoer aan te moedigen. De aandacht der landbouwers is gevestigd op gierst (Sorghum vulgare). Dit gewas, dat veel gelijkt op mais en een hoogte bereikt van zes tot tien voet, heeft als veevoer dit voor boven groene mais, dat het twee tot driemaal gesneden kan worden en dan telkens weer uitschiet. Het oogsten van 't zaad levert eenige moeilijkheden op, daar de trossen door de vogels leeggepikt worden, voor men ze oogsten kan. Men kan echter altijd wel een deel van de beplante oppervlakte zoodanig beschermen, dat men voldoende zaad krijgt voor een volgenden aanplant. Gehakseld vreten de beesten het graag. Jong gesneden, kan het moeilijk door een beter groenvoer vervangen worden. Krachtvoer is het echter niet. De landbouwers konden daarin voorzien door den aanplant van zoogenaamde cowpeas, koeboonen. (Vigna catjang). Deze, voor de tropen voortreffelijke boonensoort, die wat groeiwijze betreft veel overeenkomst heeft met onze Hollandsche bruine boonen, heeft een groeiperiode van nog geen drie maanden. En daar de landbouwers het geheele jaar door kunnen zaaien en oogsten, is het met eenige oplettendheid en eenige zorg mogelijk, viermaal in ' $t$ jaar een oogst van 't land te halen. Het beste is natuurlijk op verschillende tijdstippen te planten, om geregeld te kunnen oogsten of steeds te kunnen maaien. Heeft men een stuk voor groenvoer afgemaaid, dan kan men, als men wil den volgenden dag in den stoppel weer op nieuw planten. Het is n. 1. raadzaam, om den grond zoo weinig mogelijk bloot te laten liggen, beter is 't om na het oogsten van een gewas er weer maar dadelijk een ander gewas op te planten, om daardoor het onkruid onder den duim te houden. Het koeboonenloof is ook geen krachtvoer. Het eiwitgehalte is niet hooger, dan van onze goede grassoorten, $2,3 \%$ maar het wordt met graagte gegeten. Maait men het loof 
af, in den tijd, waarin er al wat rijpe peulen aan zitten, en dit verdient alle aanbeveling, dan wordt de voederwaarde niet onaanzienlijk verhoogd, daar de boontjes een tienmaal hooger gehalte aan eiwit hebben dan het loof.

Het landbouwdepartement heeft verder ook de aandacht gevestigd op een voedergewas, dat in Cuba sterk gepropageert wordt. Het is ook een peulgewas (Desmodium asperum). De Cubaansche variëteit (Desmodium leiocarpum), waarvan enkele exemplaren in den Cultuurtuin te zien zijn en waarover Dr. Calvinio, directeur van het landbouwproefstation in Havanna, een lijvig boekje schreef, is wat opbrengst en bladrijkdom betreft, minder waard dan de Surinaamsche Desmodium Asperum. De plant eischt weinig zorg. Men zaaie het zaad liefst op beschaduwden grond, bijv. in bananenvelden, die men niet meer als zoodanig in cultuur neemt. De plant is een langzame groeier, in 't begin althans. Snijdt of maait men haar af, als ze drie maanden oud is, dan kan men over twee maanden weer een behoorlijke snit er afhalen tot vier-vijf maal toe. Het vee vreet het loof graag. Bovendien is de plant een goede stikstof verzamelaar.

Binnen niet al te langen tijd zullen de veehouders, op de Julianahoeve zaden van Gierst, Koeboonen en Desmodium in overvloed kunnen krijgen. Maken de boeren daarvan gebruik, en leggen ze zich toe op den verbouw van genoemde voedergewassen, dan zal de voedering van hun vee aan betere eischen voldoen en de melkopbrengst hunner koeien aanzienlijk stijgen.

(Wordt vervolgd). 